\title{
TEACHERS' NARRATIVES ABOUT WORKING WITH CHILDREN WITH CANCER IN A HOSPITAL SCHOOL
}

\section{Konieczna}

\section{The Maria Grzegorzewska University (POLAND)}

Over the last decades, cancer has become one of the major health problems. According to statistical data, they are the second leading cause of death in Poland and in the world also among

children.

A medical facility is one of the basic and the most important institutions providing care for patients constituting the health care system. Due to the specificity of functioning, it can be included to a total institutions. The hospitalized person assumes a specific role - the role of the patient, thus being excluded from other roles, and each of the actions taken by him are strictly defined and subordinated to the treatment process. In the structure of hospitals and sanatoriums in Poland, there are hospital schools. A student subjected to the hospitalization process has the same right to education as a healthy student. The basic goals and tasks of hospital schools are convergent with the objectives and tasks of public schools. They strive for comprehensive development of students, taking into account their psychophysical predispositions. Students of hospital schools continue the curriculum of their public school, because in the light of the law they remain pupils of public schools, a school located at the hospital is a "temporary" school. Thanks to the participation in didactic activities organized in the medical institution, the educational arrears of the hospitalized pupils are possible to catch up. Due to this, patients can continue their education at their former school after the treatment process. This is especially important when the hospitalization process takes a long time and is associated with numerous limitations in everyday functioning. It should be remembered that the most important task that should be carried out by each school in the medical facility is to actively participate in the life of a student with a chronic illness. It is connected with the necessity of cooperation of all hospital employees in order to improve the child's health and well-being. The primary goal pursued by hospital is to heal. The teachers who work with the children in the hospital prepare the students for the tasks with which will face them immediately after they will leave the medical centre and will return to school in his place of residence.

The article will present the results of pilot studies conducted among teachers of early 
childhood education who work in the oncology ward. The research had qualitative character and proceeded in the convention of methodology of grounded theory.

The primary goal of the research was to get to know teachers' experiences about working with children with cancer (at different stages) in a hospital school.

The main research problem focused primarily on the question: What experiences reveal teachers in working with children with cancer in a treatment facility and what factors influence how they perceive their role?

keywords: teacher, child with oncologic disease, hospital school. 